\title{
Evidence for Centripetally Shifting Terminals on the Tectum of Postmetamorphic Rana pipiens
}

PETER F. HITCHCOCK AND STEPHEN S. EASTER, JR.

Department of Biology (S.S.E.) and The School of Medicine, Department of Ophthalmology, W.K. Kellogg Eye Center (P.F.H.), The University of Michigan, Ann Arbor, Michigan 48105

\begin{abstract}
In larval frogs the retina and tectum grow in topologically dissimilar patterns: new cells are added as peripheral annuli in the retina and as caudal crescents in the tectum. Retinotopy is maintained by the continual caudalward shifting of the terminals of the optic axons. After metamorphosis the pattern of growth changes. The retina continues to add new ganglion cells peripherally, but there is no neurogenesis in the tectum. To maintain retinotopy in postmetamorphic frogs, the terminals of the optic axons must continually shift toward the central tectum.

We tested the proposal of centripetally shifting axons by making punctate injections of horseradish peroxidase (HRP) in the tectum of adult Rana pipiens and observing the patterns of filled cells in the contralateral retina, as was done in the goldfish (Easter and Stuermer, '84). Punctate applications of HRP in the tectum should be taken up: 1) by fascicles, and label a partial anulus of cells, 2) by terminals, and label a cluster of cells in the corresponding retinotopic site, and 3) by the extrafascicular axonal segments, and label a band of cells connecting the partial annulus to the cluster. If the terminals have shifted centripetally, the band of cells labeled through their extrafascicular segments should have a spoke-like orientation, with the center of the retina as the hub. As the tectal site moves from rostral to caudal, this band of cells should move, pendulum-like, from temporal to nasal retina.

In general, the patterns of HRP-filled retinal cells we observed were consistent with our predictions. In adddition, HRP taken up by the oldest (rostral) tectal axons produced more complex patterns of filled cells that indicated that these axons had shifted both caudally before metamorphosis and centripetally after.
\end{abstract}

Key words: frog, retinotectal projection, sliding connections, neuronal plasticity, horseradish peroxidase

The retina and tectum grow in topologically dissimilar patterns in larval frogs (tadpoles) and fish (Gaze et al., '74, '79; Meyer, '78; Raymond and Easter, '83; Rayond, '86). New cells are added in an annulus at the margin of the retina (e.g., Hollyfield, '68; Johns, '77; Straznicky and Hiscock, '84), and in a horseshoe-shaped zone at the caudomedial border of the tectum (e.g., Currie, '74; Raymond and Easter, '83). Gaze et al. ('74, '79) were the first to point out that retinotopy was maintained throughout this growth, and therefore, the terminals of retinal axons must continually shift caudomedially across the tectum. Although initially disputed (Jacobson, '76), "sliding" retinotectal connections have been demonstrated directly in larval frogs (Fraser '83; Reh and Constantine-Paton, '83, '84; Fraser and Hunt, '86; see also Scott and Lazar, '76; Longley, '78; Gaze et al., '79) and indirectly in fish (Cook et al., '83; Easter and Stuermer, '84; Stuermer, '84; Raymond, '86).

Accepted June 4, 1987.

Address reprint requests to Peter F. Hitchcock, Ph.D., The School of Medicine, Department of Ophthalmology, The University of Michigan, W. K. Kellogg Eye Center, Ann Arbor, MI 48105-1994. 
In postmetamorphic frogs, the tectum does not add neurons (Grant and Keating, '86; Reh, personal communication), but the retina continues to add new ganglion cells (Maturana et al., '60; Reh and Constantine-Paton, '83; Straznicky and Hiscock, '84; Grant and Keating, '86). Electrophysiological mapping experiments indicate that the most peripheral (newest) ganglion cells project to the edge of the tectum. Therefore, it seems likely that axon terminals near the tectal periphery must shift centrally as new retinal axons arrive (Constantine-Paton, et al., '83). We have tested that prediction by making punctate applications of horseradish peroxidase (HRP) to the tectum of adult frogs, and then examining the pattern of labeled retinal ganglion cells, after Easter and Stuermer ('84).

We assume that each wave of new axons grows in along the edge of the tectum, as in goldfish (Stuermer and Easter, '84) and synapses initially near the edge, in a retinotopic location. As subsequent generations of axons arrive, they behave similarly and displace the terminals of their predecessors toward the central tectum. These terminals, in their turn, displace their predecessors to more central locations, and so on. By analogy with goldfish (Easter and Stuermer, '84), we anticipate that each retinotectal axon will have three fairly distinct tectal segments: 1) the fascicular portion (in the stratum opticum or along the tectal edge, depending on whether the axon arrived before or after tectal neurogenesis ceased), 2) the extrafascicular portion (in the synaptic layer, passing through all those sites where the axon once terminated), and 3) the current terminal.

If the above model is correct, punctate applications of HRP in the tectum will label three different populations of ganglion cells (see Easter and Stuermer, '84). 1) Ganglion cells of the same generation whose axons share a common fascicle will be labeled as fascicular axons of passage through the application site. For injections made in the dorsal tectum (see below), these cells will form a portion of a hemiannulus in the ventral retina (Reh et al., '83; Stuermer and Easter, '84). 2) Ganglion cells whose terminals occupy the injection site will be labeled. These cells will cluster at the retinotopically corresponding position in the retina. 3) Ganglion cells whose extrafascicular axons pass through the injection site will be labeled. These are the cells that previously terminated in the injection site, but have since moved.

The model and its predictions are very similar to those for the goldfish (Easter and Stuermer, ' 84 ). But the different geometry of growth in the postmetamorphic frog leads to different specific predictions, developed in the diagram of the tectum and retina in Figure 1. The lower semicircle represents the right, ventral hemiretina. The upper semicircle represents the left, dorsal hemitectum, onto which the right hemiretina projects. The drawings are oriented so that the topographic mapping is symmetric across the boundary between the two. For simplicity, two fascicles (f1 and $\mathrm{f} 2$ ) in the hemitectum have been illustrated. The stippled semiannulus in the tectum represents the hypothetical termination sites of the axons contained in fascicle f2. The dashed lines represent the extrafascicular segments of the axons whose terminals originally synapsed near the fascicle but have subsequently shifted centrally. Consider now the four labeling sites (1-4) in the tectum, and, respectively, the resulting patterns of labeled cells $\left(1^{\prime}-4^{\prime}\right)$ in the retina. (For convenience the injection sites 2-4 pass through a single fascicle, $\mathrm{f} 2$; therefore, cells that form patterns $2^{\prime}-4^{\prime}$ will share progressively smaller proportions of the same partial annulus, respectively.)

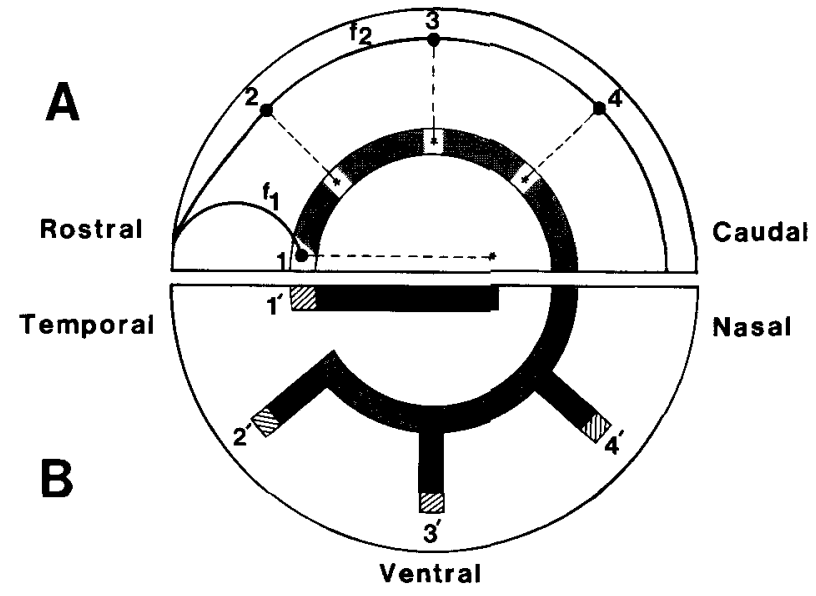

Fig. 1. Schematic representation of the model of shifting connections. A. Dorsal left hemitectum. B. Right ventral hemiretina. In A, f1 and $f 2$ represent two fascicles of optic fibers on the tectal surface. The dashed lines represent the extrafascicular segments of axons that terminate in tectal locations (shaded hemiannulus), central to the fascicle. 1, 2, 3, and 4 are sites on the tectum where the application of HRP is predicted to retrogradely fill ganglion cells that form the patterns (in B) originating at retinal locations $1^{\prime}-4^{\prime}$, respectively. In $B$, the areas with cross hatching, dark, and light shading indicate the locations of cells filled with HRP taken up through their terminals, extrafascicular segments, and fascicular axons, respectively. (See text for details.)

Horseradish peroxidase applied at site 1 will produce the pattern of filled cells labeled $1^{\prime}$. Site 1 lies near the representation of the horizontal meridian, and because nearly all the axons contained in fascicle $\mathrm{fl}$ have exited rostral to site 1, they will not be damaged and filled with HRP. As a result, pattern 1' has no annular component. HRP applied here will label cells in temporal retina (cross-hatched zone) through their terminals, and a horizontal band of cells (solid zone) extending into nasal retina, through their extrafascicular axons (dashed line). Since the fascicle fl enclosed the entire tectum when its axons initially grew in (before metamorphosis), site 1 previously received the terminals from cells in nasal retina. For this reason the cells labeled through their extrafascicular axons will form a band that extends into nasal retina.

Horseradish peroxidase applied at site 2 will produce the pattern originating at 2 . Since fascicle $f 2$ contains axons destined for more caudal tectum, these will take up the HRP, and a long partial annulus of retinal cells (shaded zone) will be labeled that originates in the nasal retina and extends into temporal retina. The cells whose axons currently terminate at site 2 will be labeled and will occupy the retinotopically corresponding position (cross-hatched zone at $2^{\prime}$ ). The previous generations of cells whose extrafascicular axons passed through site 2 , but have since moved centrally, will be labeled (solid zone) and will form a band that connects the peripheral cells labeled through their terminals with the central annulus of cells labeled through their fascicular axons.

Horseradish peroxidase applied to sites 3 and 4 will produce similar patterns to the one from site 2 , but with smaller annular portions (see Easter and Stuermer, '84, for details). With respect to the patterns of HRP-filled cells predicted by our model, there are two important features that reflect the centripetal movement of the terminals. First, the cells filled through their extrafascicular axons will form a band oriented radially about the retinal center. 

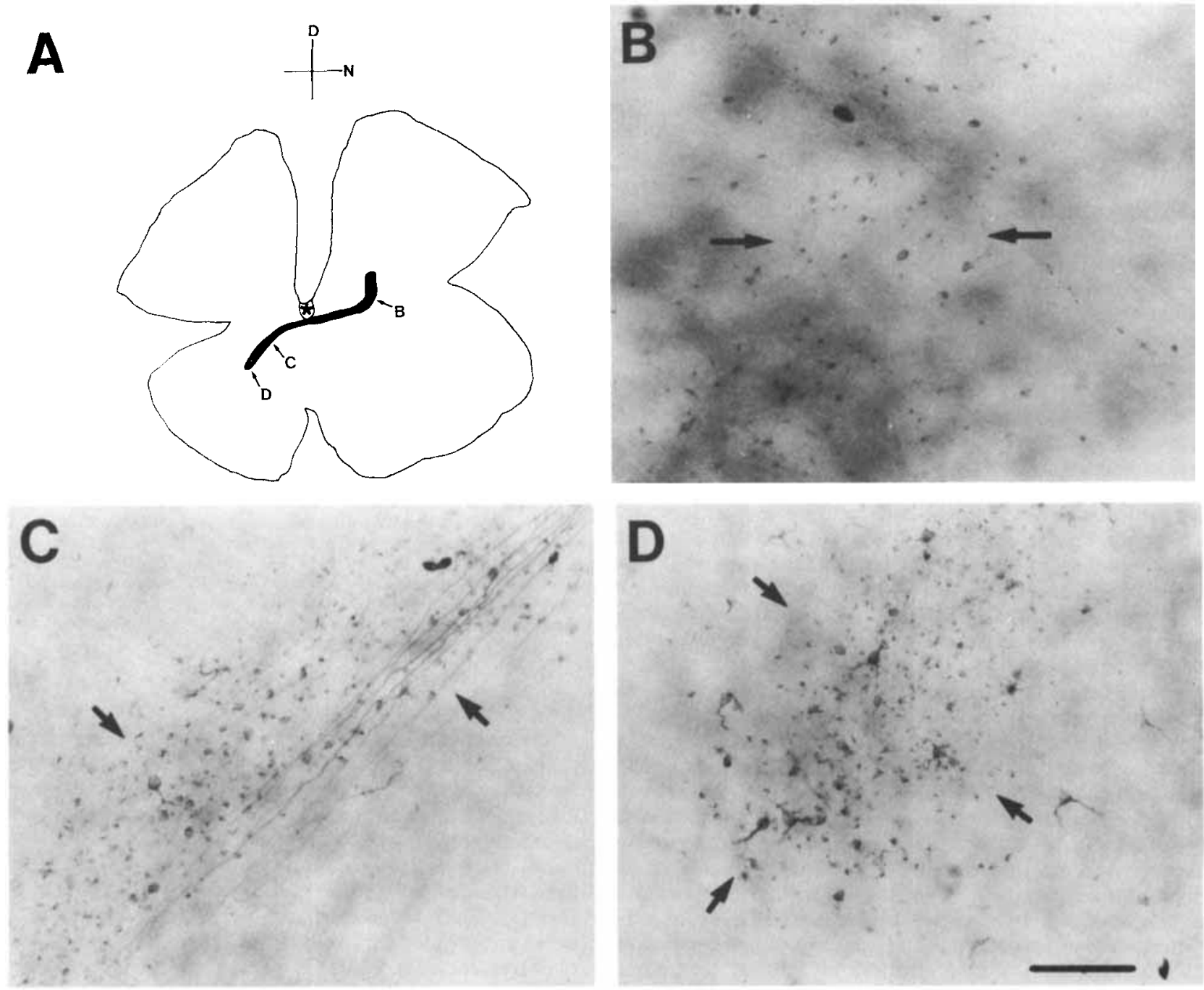

Fig. 2. A is a camera lucida tracing of a wholemounted retina showing the pattern of HRP-filled cells (filled-in zone); letters B, C, and D indicate regions of the pattern of HRP-filled cells illustrated in panels B, C, and D, respectively. D, dorsal; N, nasal; asterisk marks the optic disc; scale bar equals $2.0 \mathrm{~mm}$. B, C, D. Photomicrographs showing HPR-filled cells within the partial annulus $(B)$, the radially oriented band $(C)$, and the peripheral end of the pattern of filled cells (D); see text for details. Arrows indicate the boundaries formed by the filled cells. Scale bar equals $0.1 \mathrm{~mm}$.

Second, as the injection site moves from rostral to caudal tectum ( 2 to 3 to 4 ), the band of labeled cells will move, pendulum-like, from temporal to nasal retina $\left(2^{\prime}\right.$ to $3^{\prime}$ to $\left.4^{\prime}\right)$.

The above model describes the centripetal movement of axons added after metamorphosis. However, in the rostral (oldest) tectum there will be a population of axons that were added before metamorphosis. These axons will have had a more complex pattern of movement. For those lying on the representation of the horizontal meridian, the direction of movement will have always been toward caudal tectum (see Constantine-Paton et al., '83; Fig. 1). For the more peripheral rostral axons, their initial (premetamorphic) movement will have been caudally directed, whereas their subsequent (postmetamorphic) movement will have been centripetally directed. Punctate injections of HRP that label this latter group should produce patterns in the retina indicating both directions of movement; i.e., labeled bands with a nasotemporally oriented segment (premetamorphic movement) and a radially oriented one (postmetamorphic movement). Moreover, the annular portion should have a small radius, as these axons grew in when the retina was small.

\section{MATERIALS AND METHODS}

Horseradish peroxidase was applied to the tecta of adult Rana pipiens (3-3.5 inches from nose to anus; Kons Scientific, Madison, WI) as follows: A slurry of HRP (Miles) in 5 $\mu \mathrm{l}$ of $2 \%$ dimethylsulfoxide in distilled water was made, and a bead of this solution was applied to the end of a fine insect pin by repeatedly dipping the pin into the slurry. As the HRP on the pin was drying, the animals were anesthetized by immersion in $0.2 \%$ tricaine methanesulfonate, then placed under a stereo microscope, and draped with a moist towel. The left tectum was exposed by drilling a hole through the skull, and the overlying dura was removed. The HRP-coated insect pin was inserted into the tectal neuropil and left in position for a minute or less. Following this step, the skull opening was packed with gel foam, and 


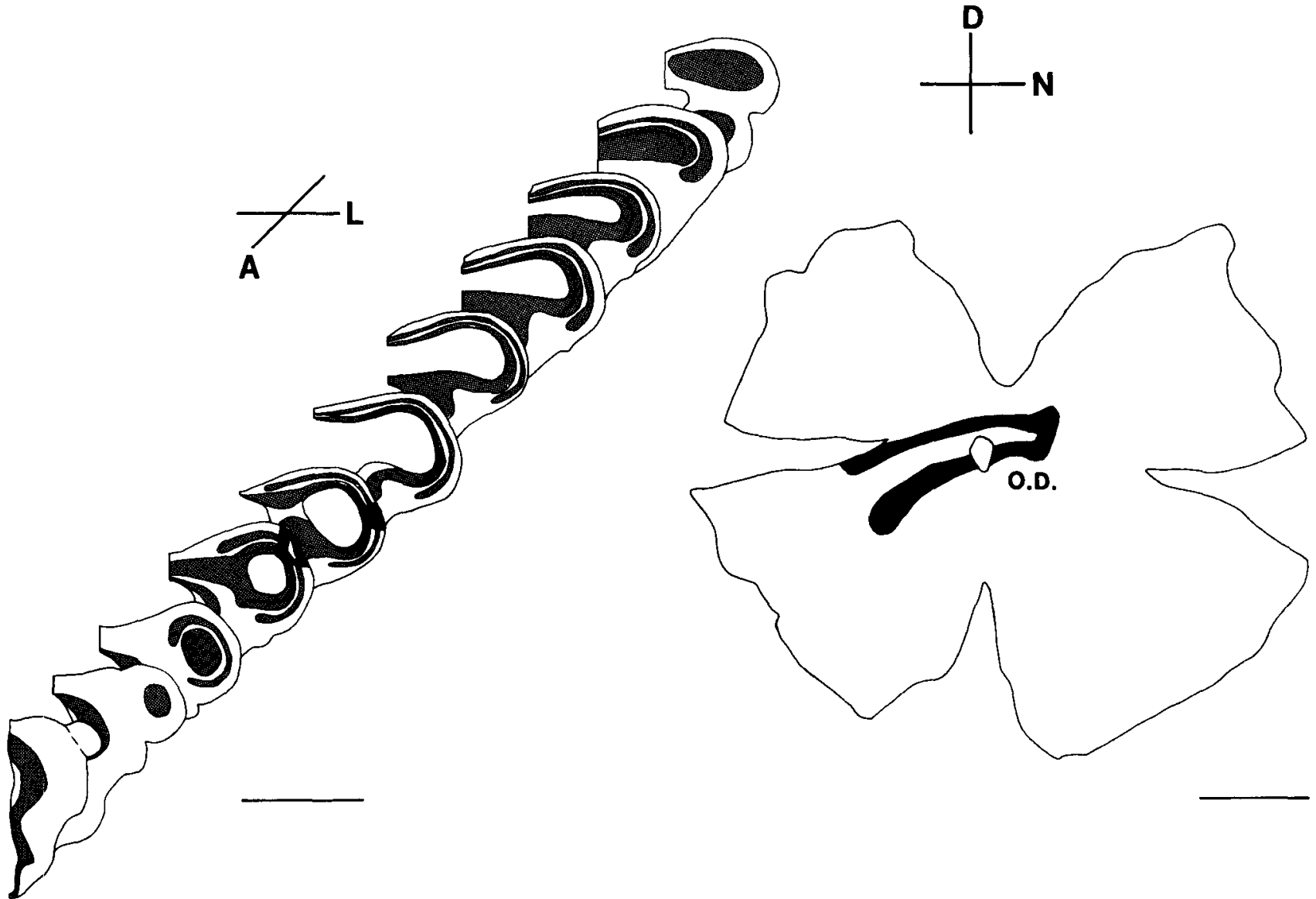

Figs. 3-6 and 8. Left: Camera lucida tracings of a 1 in 4 series of coronal sections through the tecta of adult frogs. The sites of HRP application are indicated as filled-in zones passing through the tectal layers. Stippling indicates cellular layers. A, anterior; L, lateral. Right: Camera lucida tracings of wholemounted retinae showing the patterns (filled-in zones; see text for details) formed by cells filled with HRP following applications of HRP to their respective, contralateral tectum. Arrowheads in Figure 4 indicate the extent of the partial annulus. O.D., optic disc; D, dorsal; N, nasal. Scale bars equal $2 \mathrm{~mm}$.

Fig. 3. Pattern of filled retinal cells (right) observed following an injection of HRP in rostrocentral tectum (left). the skin was sutured. All HRP injections were restricted to the dorsal aspect of the left tectum. Five days later each animal was re-anesthetized and perfused transcardially with phosphate buffer. The right eye was removed and placed into cold phosphate buffer in a refrigerator, and the animal was perfused a second time with $2-4 \%$ glutaraldehyde in $0.2 \mathrm{M}$ phosphate buffer, $\mathrm{pH}$ 6.9. After the second perfusion, the brain was exposed, and the head was immersed in the fixative.

The procedures used to isolate and fix each retina for HPR histochemistry are identical to those described earlier (Hitchcock and Easter, '86). Briefly, the cornea and lens were removed, dorsal and ventral orienting cuts through the vertical meridian were made, and the retina was isolated from the sclera and pigment epithelium in a phosphate buffer. The isolated retina was wholemounted, receptor side down, onto a gelatinized slide, and fixed in $2 \%$ glutaraldehyde in a $0.2 \mathrm{M}$ phosphate buffer for 30 minutes. After the fixation, the vitreous was gently brushed off, and the retina was dried slightly so that it would adhere to the slide. Each retina was stored overnight in the phosphate buffer in the refrigerator. No obvious distortions (other than flattening) of the retina resulted from these procedures.
After fixing the retina, the brain was removed from the skull and cryoprotected by placing it overnight in cold fixative containing $30 \%$ sucrose. The brain was frozen and sectioned in the frontal plane at $50 \mu \mathrm{m}$, and the sections were collected in a phosphate buffer and mounted serially onto gelatinized slides. The retina and brain sections were reacted together using cobalt intensification and $3-3^{\prime}$ diaminobenzidine (DAB) as the chromogen (Adams, '77). After the $\mathrm{DAB}$ reaction, the brain sections were counterstained in $0.25 \%$ toluidine blue, and together with the retina, dehydrated in alcohol, cleared in xylenes, and coverslipped with Histoclad (Clay Adams).

For each animal, camera lucida drawings were made of the right retina and every fourth brain section at $50 \times$ magnification. For the retina, the boundaries that enclosed the HRP-filled ganglion cells were located by systematically scanning the retina at $250 \times$ magnification. On the camera lucida drawing, points were marked where the HRPfilled cells were initially encountered and where their planimetric density changed noticeably. In general this results in two boundaries. The outer one enclosed all the HRPfilled cells, and the easily distinguished inner one enclosed cells that were more densely filled with the reaction prod- 


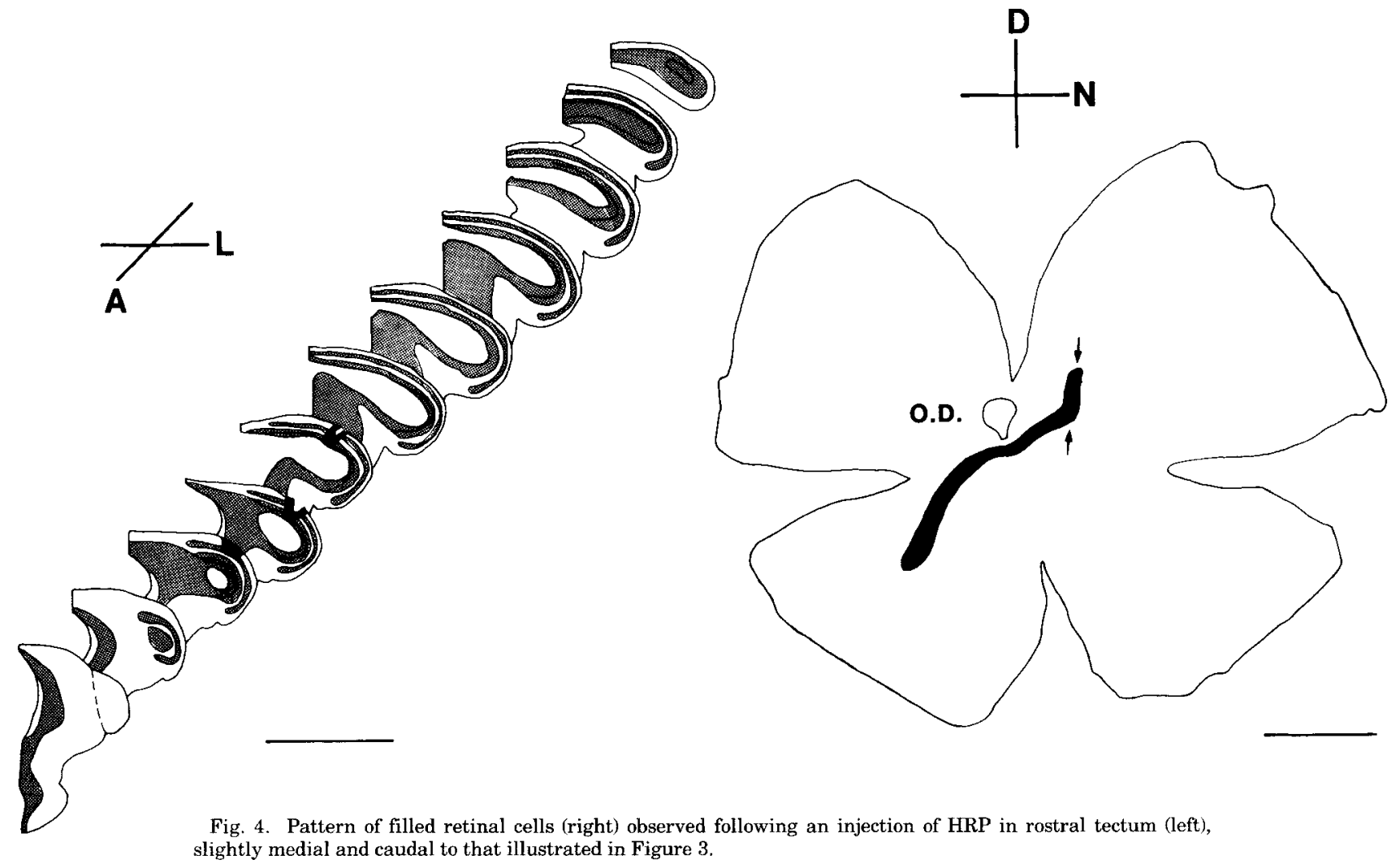

uct (Fig. 2). The outer boundary was variable and produced no discernable pattern. The inner boundary formed a distinct pattern that changed predictably with variations in the tectal labeling site (see below). We assume that the filled cells outside the inner boundary filled nonspecifically, whereas those inside it had axons and terminals that were damaged and took up the HRP at the tectal injection site. For reasons of clarity only their locations are illustrated.

\section{RESULTS}

Labeled ganglion cells were seen in 21 of 29 animals in which HRP was applied to the tectum. For 4 of these animals the label in the retina was too light to discern any pattern, and they are omitted from the following decriptions. The remaining animals fell into two groups (see below), one group (13 animals) in which the pattern of labeled cells resembled that predicted by our model, and a second group (4 animals) in which the patterns observed were not predicted.

Figure 2 (panel A) illustrates the pattern of HRP-filled cells seen following an application of HRP to a rostrolateral site on the contralateral tectum. Panels B, C, and D are photomicrographs showing the HRP-filled cells at the locations shown in panel A, repectively. The photomicrographs illustrate two general features of the patterns of HRP-filled cells. First, the inner boundary of the filled cells (see above), and thereby the patterns formed, were easily discerned. Second, within these patterns there were regional variations in the planimetric density of the HRP-filled cells. The planimetric density was lowest within the partial annulus (Fig. 2B), intermediate within the band of cells (Fig. 2C), and highest at the end that lay in the peripheral retina
(Fig. 2D). According to the model, these three regions correspond to cells labeled through their fascicular axons, extrafascicular axons, and terminals, respectively. Although axons were not visibly bundled in the tectum of Rana, as they are in the goldfish (probably because most axons are unmyelinated in the frog, and therefore less visible), partial annuli of ganglion cells were filled from single injection sites in the tectum, indicating that the axons of similarly aged cells are in close proximity. This observation supports our assumption that the mode of axon ingrowth in the frog's tectum is similar to that in fish (Stuermer and Easter, '84).

Figures 3-6 illustrate the data from 4 (of 13) experiments in which HRP was applied to the tectum along a line roughly parallel to the representation of the horizontal meridian. [Unlike the schematic in Figure 1A, the tecta in Rana are oriented obliquely to the long axis of the body and the representation of the horizontal meridian runs from rostrolateral to caudomedial tectlim (Gaze, '58; Jacobson, '62).] On the left and right of each figure are illustrated a 1 in 4 series of frontal brain sections, showing the site where the HRP was applied in the tectum, and the contralateral wholemounted retina, showing the pattern of retrogradely filled ganglion cells, respectively.

Figure 3 illustrates the pattern of filled cells seen in the retina of one animal in which the application of HRP was made in rostral tectum. Two horizontally oriented bands of labeled cells straddled the border between dorsal and ventral retina. These two bands originated in the temporal retina and extended, parallel, into the nasal retina where they merged. It was assumed that this pattern was produced by the uptake of HRP by axons at two different tectal sites. Inspection of the brain sections (Fig. 3) indicated that 


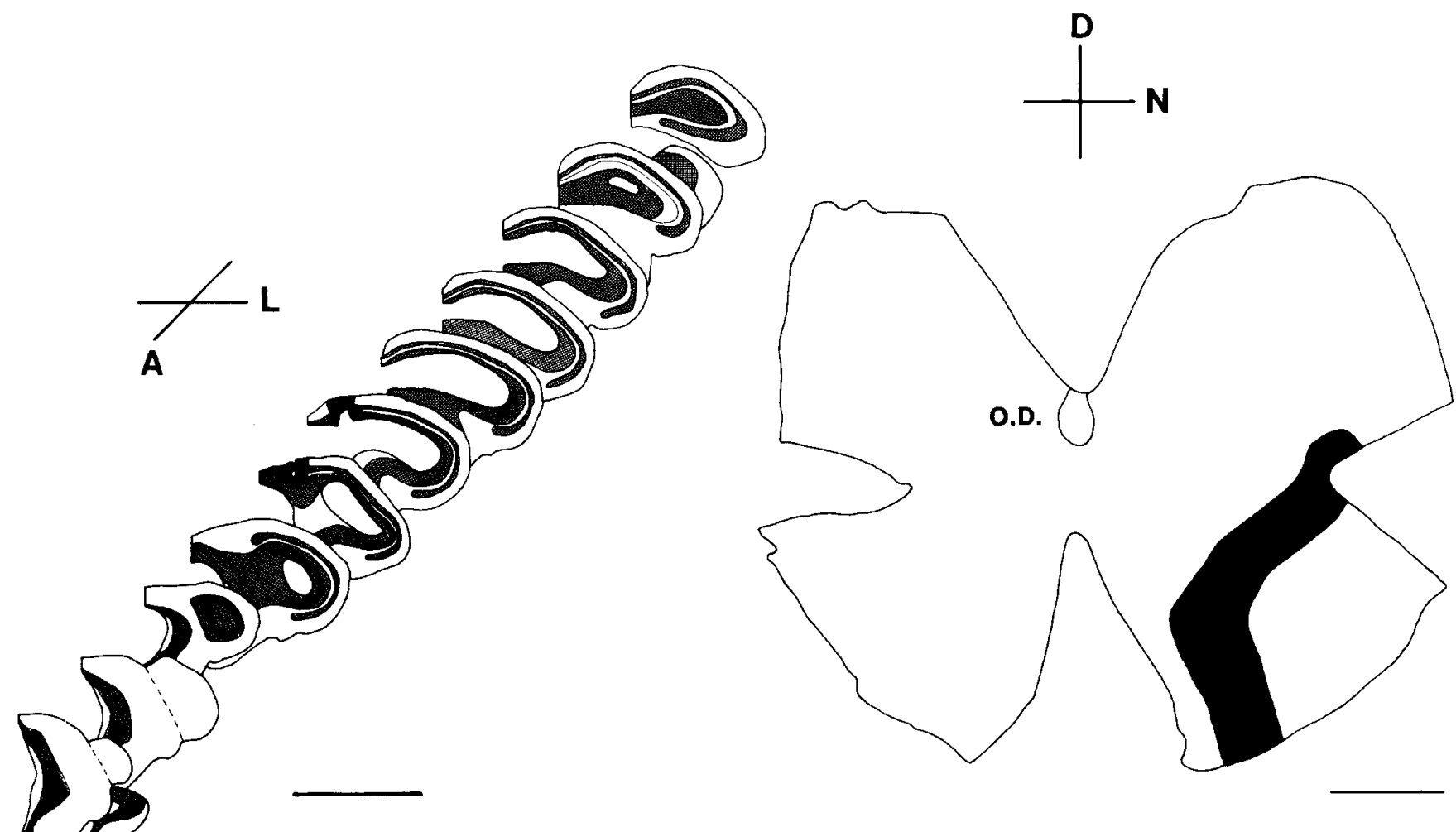

Fig. 5. Pattern of filled retinal cells (right) observed following an injection of HRP in medial tectum (left), near the representation of the vertical meridian.
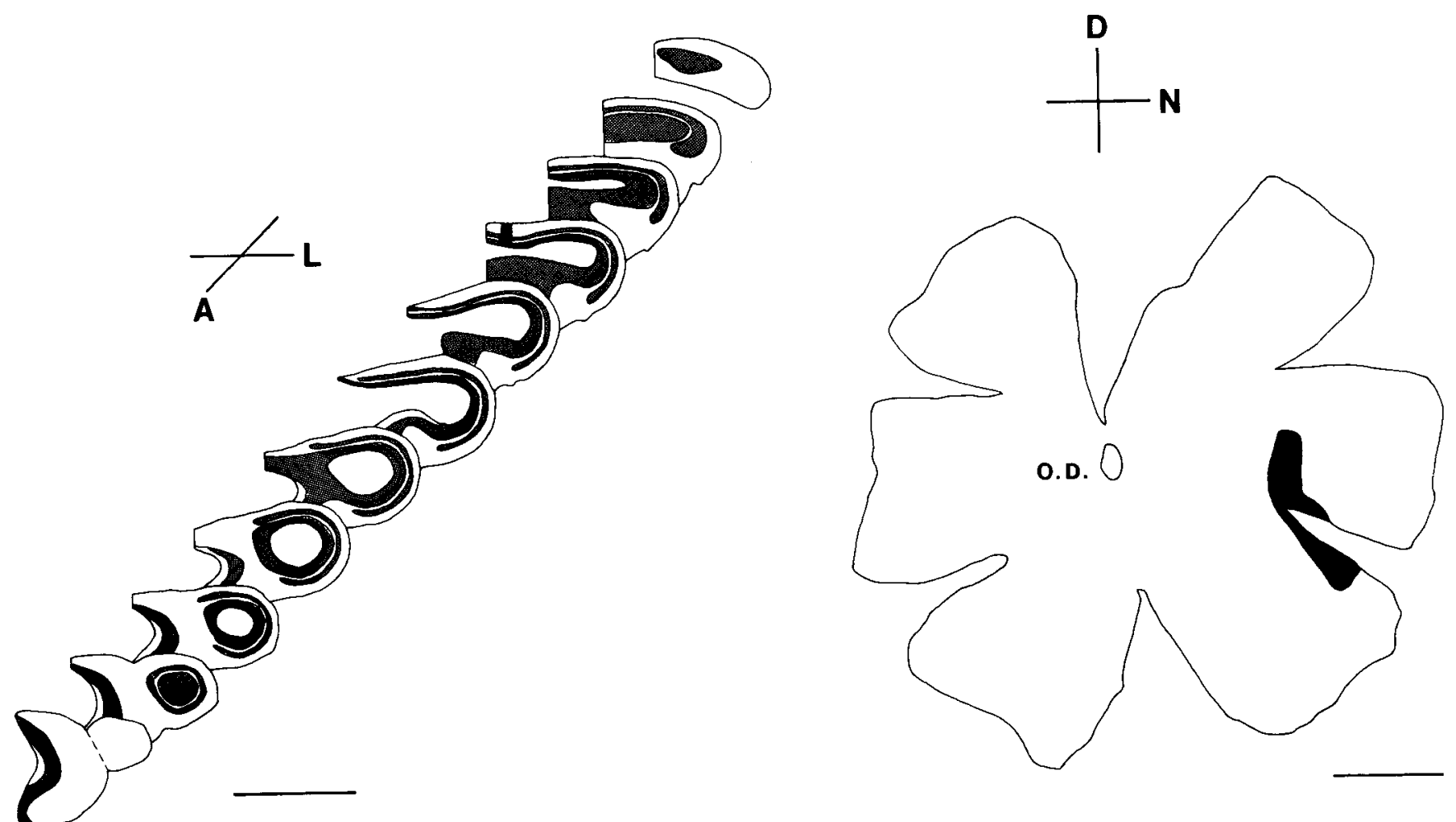

Fig. 6. Pattern of filled retinal cells (right) observed following injection of HRP in caudomedial tectum (left). 


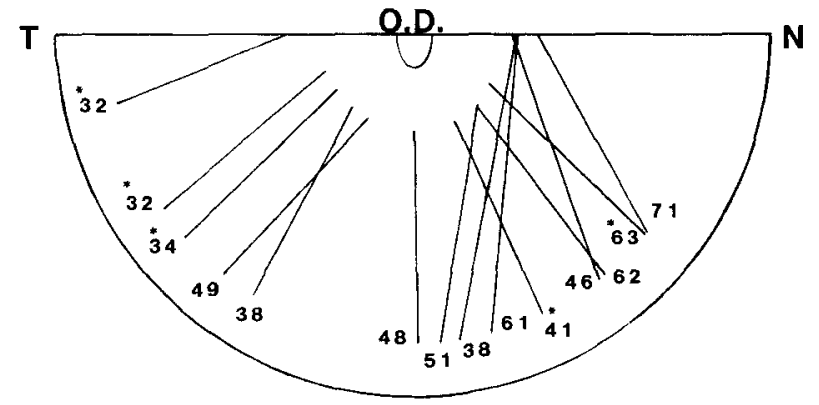

Fig. 7. Idealized ventral retina showing the orientation of the radially oriented bands of HRP-filled cells for the animals whose results met our predictions (see text). Each line was drawn through the radially oriented band of cells. The numbers adjacent to each line represent the rostrocaudal location of the tectal injection site, expressed as the percent distance between the rostral- and caudalmost sections cut through each tectum. No attempt was made to correct for the extreme curvature of the tectum at its rostral and caudal poles or for the flattening of the retina during wholemounting. The asterisks, from nasal to temporal, correspond to the orienta tion of the radial bands of cells illustrated in Figures 3-6, respectively. N, nasal; O.D., optic disc; T, temporal.

the HRP-coated pin entered the dorsal tectum obliquely, passed through the deep layers, and exited ventrally, presumably intersecting optic axons and terminals at two separate sites. (Had the pin passed more superficially, the cells between the two bands would have been labeled as well.) Regardless, the pattern formed by the filled cells approximated that predicted by our model following the application of HRP in rostral tectum near the representation of the horizontal meridian (site 1 in Fig. 1): a horizontally oriented band of cells that originates in the temporal retina, extends into the nasal retina, and lies near the dorsoventral border. This pattern is similar to that seen in the goldfish after injections of HRP in a similar tectal location (Easter and Stuermer, '84), and it is interpreted as evidence that these axons shifted caudally at all times.

Figure 4 illustrates the pattern of filled cells oberved in three animals when HRP was applied to a site slightly caudal and medial to that of Figure 3 . It had a short partial annulus in the nasal retina (arrowheads, Fig. 4), close to the optic disc, which merged with a horizontally oriented band of cells that passed into the temporal retina where it joined a radially oriented band. This pattern is consistent with our expectation that injections in the rostral tectum label the oldest axons, and these axons have shifted both caudally and centripetally. The cells in the partial annulus near to the optic disc were produced during larval life; this implies that the fascicular axons that passed through the injection site grew into the tectum when the retina was very small. The horizontal and radial components of the pattern suggest that these axons subsequently shifted both caudally, as in goldfish (Easter and Stuermer, '84) and centripetally (as described above), respectively (see also Fig. 2A).

Figure 5 illustrates the pattern of filled cells observed in three animals following the application of HRP to a midtectal site near the medial border. In this figure the partial annulus originated in the nasal retina and extended ventrally where it merged with a band of cells that was oriented adjacent to the cut through the vertical meridian. In these animals, the partial annulus was distant from the optic disc, the radial band was restricted to the nasal retina, and the pattern of filled cells had no horizontal component.
These features suggest that the axons that passed through the tectal injection site in the caudomedial tectum were relatively young, as they grew in when the retina was relatively large (and old), and subsequently only shifted centripetally.

Figure 6 illustrates the pattern of filled cells observed in six animals when HRP was applied in the caudomedial tectum. In these animals the labeled cells were confined near the nasal pole of the retina. They formed a pattern with a short, vertically oriented partial annulus, which merged with a radially oriented band of cells that extended ventronasally. Again, the partial annulus was distant from the optic disc, and there was no horizontally oriented component within the pattern of filled cells. Therefore, we judge that this group of cells was added postmetamorphically.

The data of all thirteen animals whose results were consistent with our predictions are summarized in Figure 7. It illustrates an idealized ventral retina onto which have been drawn lines showing the orientation of the radially oriented bands of cells. The numbers adjacent to each line indicate the location of the tectal injection site expressed as the percent distance between the rostral and caudal pole of the tectum. The asterisks indicate the data derived from. Fig. ures 3 (two bands) through 6 . As predicted, the bands are oriented roughly radially about the optic disk, and the more caudal injection sites produced bands in nasal retina.

We also obtained results (4 animals) that we did not predict and were unable to interpret. Following the application of HRP in the caudocentral tectum (54-79\% of the rostrocaudal extent), the filled cells formed patterns similar to that illustrated in Figure 8 . The patterns consisted of a horizontal band of cells with a variable length (sometimes nearly absent, as in Fig. 8), that joined a very short, indistinct, vertically oriented band at its temporal-most end. The horizontally oriented band of labeled cells presumably re sulted from labeling axons whose extrafascicular segments were oriented along the representation of the horizontal meridian, qualitatively similar to that shown at injection site 1 in Figure 1. However, we could not confidently assign the locations of the cells filled either through their terminals or through their fascicular segments. Due to this ambiguity, we have chosen not to attempt to interpret these patterns, and we illustrate them merely as results that were contrary to our expectations.

In summary, the data described here generally conform to our predictions (see above) and support the proposal (Constantine-Paton et al., '83) that retinotectal axons shift centripetally in postmetamorphic Rana pipiens.

\section{DISCUSSION}

Easter and Stuermer ('84) inferred the movement of optic terminals in the tectum of the goldfish, in part, by making punctate injections of HRP in the tectum and observing the resulting pattern of filled cells in the retina. We have done likewise for the adult frog. These two studies demonstrate the general effectiveness of this simple technique and support the current notions of the patterns of growth of retinotectal axons, and the plasticity of this projection in lower vertebrates. Further, we were able to distinguish the patterns of filled retinal cells formed by axons that entered the tectum before metamorphosis from those that entered after. Those that we inferred to have entered the tectum before metamorphosis were labeled in the oldest (rostral) tectum and produced complex patterns within the retina, indicating that they had shifted both caudally and centripetally. 

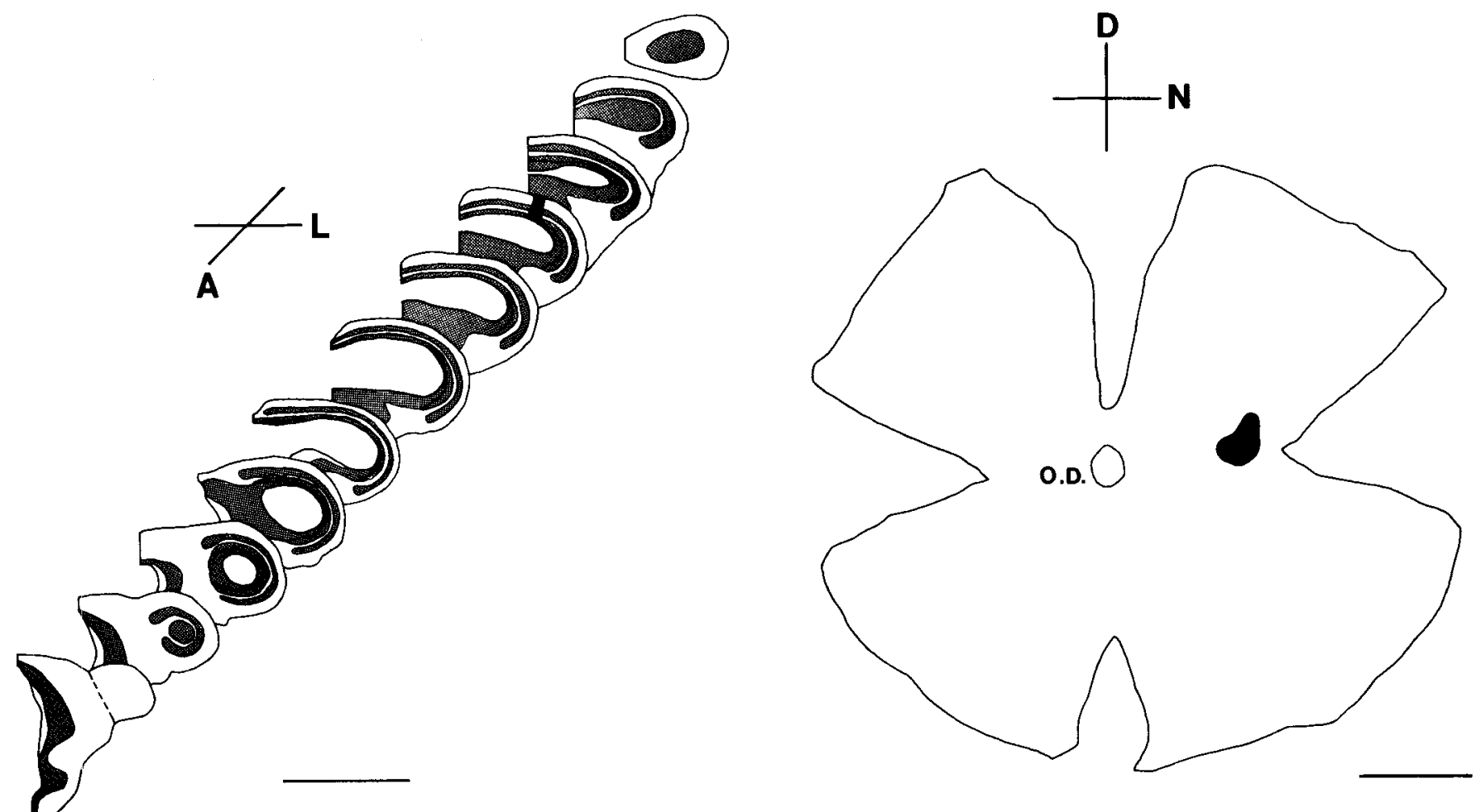

Fig. 8. Pattern (right) of filled retinal cells observed following the injection of HRP in caudocentral tectum.

Those axons that we inferred to have entered at or after metamorphosis were labeled in the peripheral tectum and produced patterns indicating their centripetal movement.

Morphological evidence for our model of centripetally shifting axons is provided by Constantine-Paton et al. ('83). They compared the morphology of intratectal axons in young (up to 3 months past metamorphosis) and adult ( $>1$ year) Rana. In the young animals the axons at all tectal locations were oriented rostrocaudally. In the adults the axons in the rostral and central tectum maintained their rostrocaudal orientation, whereas the axons in more peripheral and caudal regions of the tectum made abrupt, right-angle turns as they exited the optic tracts to assume a radial orientation. In addition, the radially oriented axons had elongated, bare branches that joined the terminal arbor to the parent axon, similar to the extrafascicular axons seen in the goldfish (Stuermer, '84; Easter and Stuermer, '84).

In fish and larval frogs, the caudalward shifting of the terminals can be accounted for by two different influences: 1) new terminals added in the rostral tectum may "push" the projection, or 2) the crescent of newly generated, uninnervated tissue at the caudomedial pole of the tectum may 'pull' the projection. The first mechanism implies that in the rostral tectum the new terminals encounter the old ones and displace them, whereas the second mechanism suggests that the new tissue attracts axons. Either or both influences might be at work, and when both rostral crowding and caudal vacancies exist, as in fish and tadpoles, one carınot be sure that either applies.

The observation that the projection from a surgically created half retina expands to fill the tectum (Schmidt et al., '78) indicates that "pull" alone can work. But the reciprocal operation, surgical creation of a half tectum, does not lead to an orderly compression of the entire retinal projection unless one optic nerve is interrupted at the same time (Gaze and Sharma, '70). Therefore, the ability of interfiber interactions to expel terminals has not been established in the central nervous system.

Our observations indicated that interfiber interactions can play a role, because in postmetamorphic frogs, with no tectal neurogenesis, "push" is unaccompanied by "pull." Our results are consistent with the model of Schmidt et al. (78), which is based on only three assumptions. They are: 1) each optic fiber has an intrinsic tendency to expand its terminal arbor, 2) this is opposed by other nearby terminals, and 3) smaller terminal arbors have a competitive advantage over larger ones. Accordingly, in Rana, the new axons growing to their retinotopic sites on the edge of the tectum will have small terminals that partially displace the older, larger residents. These displaced terminals, having lost a portion of their synaptic territory, gain a competitive advantage, and in turn displace their more central neighbors. As a result, the addition of new terminals at the tectal margin drives the entire population centrally.

\section{ACKNOWLEDGMENTS}

We thank Drs. R. Bernhardt, P. Raymond, and T. Reh for useful discussions, C. Martonyi for photographic assistance, and L. Hosman for secretarial assistance. This work was supported by grant EY-00168 to S.S.E., and a postdoctoral fellowship EY-05625 and NSF grant BNS-8607886 to P.F.H.

\section{LITERATURE CITED}

Adams, J.C. (1977) Technical considerations on the use of horseradish peroxidase as a neuronal marker. Neurosci. 2:141-145.

Cook, J.E., E.C.C. Rankin, and H.P. Stevens (1983) A pattern of optic axons in the normal goldfish tectum consistent with the caudal migration of 
optic terminals during development. Exp. Brain Res. 52:147-151.

Constantine-Paton, M., C. Pitts, and T.A. Reh (1983) The relationship between retinal axon ingrowth, terminal morphology, and terminal patterning in the optic tectum of the frog. J. Comp. Neurol. 218:297-313.

Currie, J.R. (1974) Some observations on the early development of the visual system in the frog, Rana pipiens. Ph.D. Thesis, Washington University.

Easter, S.S., Jr., and C.A.O. Stuermer (1984) An evaluation of the hypothesis of shifting terminals in goldfish optic tectum. J. Neurosci., 4:10521063

Fraser, S.E. (1983) Fiber optic mapping on the Xenopus visual system: Shift in the retinotectal projection during development. Dev. Biol. 95:505511.

Fraser, S.E., and R.K. Hunt (1986) A physiological measure of shifting connections in the Rana pipiens retinotectal system. J. Embryol. Exp. Morph. 94:149-161.

Gaze, R.M. (1958) The representation of the retina on the optic lobe of the frog. Quart. J. Exp. Physiol. 43:209-214.

Gaze, R.M., and S.C. Sharma (1970) Axial differences in the reinnervation of the goldfish optic tectum by regenerating optic nerve fibers. Exp. Brain Res. 10:171-181.

Gaze, R.M., M.J. Keating, and S.-H. Chung (1974) The evolution of the retinotectal map during development in Xenopus. Proc. R. Soc. Lond. B 185:301-330.

Gaze, R.M., M.J. Keating, A. Ostberg, and S.-H. Chung (1979) The relationship between retinal and tectal growth in larval Xenopus: Implications for the development of the retino-tectal projection. J. Embryol. Exp. Morph. 53:103-143.

Grant, S. and M.J. Keating (1986) Ocular migration and the metamorphic and postmetamorphic maturation of the retinotectal system in Xenopus laevis: An autoradiographic and morphometric study. J. Embryol. Exp. Morph. 92:43-69

Hitchcock, P.F., and S.S. Easter, Jr. (1986) Retinal ganglion cells in goldfish A qualitative classification into four morphological types, and a quantitative study of the development of one of them. J. Neurosci. $6: 1037$ 1050

Hollyfield, J.G. (1968) Differential addition of cells to the retina in Rana pipiens tadpoles. Dev. Biol. 15:163-179.

Jacobson, M. (1962) The representation of the retina on the optic tectum of the frog. Correlation between retinotectal magnification factor and retinal ganglion cell count. Quart. J. Exp. Physiol, 47:170-178.

Jacobson, M. (1976) Histogenesis of retina in the clawed frog with implica- tions for the pattern of development of retinotectal connections. Brain Res. 103:541-545.

Johns, P.R. (1977) Growth of the adult goldfish eye. III. Source of the new retinal cells. J. Comp. Neurol. 176:343-358.

Longley, A. (1978) Anatomical mapping of retino-tectal conections in developing and metamorphosed Xenopus: Evidence for changing connections. J. Embryol. Exp. Morph. 45:249-270.

Maturana, H.R., J.Y. Letvin, W.S. McCulloch, and W.H. Pitts (1960) Anatomy and physiology of vision in the frog (Rana pipiens). J. Gen. Physiol. (Suppl.) 43:129-175.

Meyer, R.L. (1978) Evidence from thymidine labeling for continuing growth of retina and tectum in juvenile goldfish. Exp. Neurol. 59:99-111.

Raymond, P.A. (1986) Movement of retinal terminals in goldfish optic tectum predicted by analysis of neuronal proliferation. J. Neurosci. 6:24792488 .

Raymond, P.A., and S.S. Easter, Jr. (1983) Postembryonic growth of the optic tectum in goldfish. I. Location of germinal cells and numbers of neurons produced. J. Neurosci. 3:1077-1091.

Reh, T.A., and M. Constantine-Paton (1983) Qualitative and quantitative measures of plasticity during the normal development of the Rana pipiens retinotectal projection. Dev. Brain Res. 10:187-200

Reh, T.A., and M. Constantine-Paton (1984) Retinal ganglion cell terminals change their projection sites during larval development of Rana pipiens. J. Neurosci. 4:442-457.

Reh, T.A., E. Pitts, and M. Constantine-Paton (1983) The organization of the fibers in the optic nerve of normal and tectum-less Rana pipiens J. Comp. Neurol. 218:282-296.

Schmidt, J.T., C.M. Cicerone, and S.S. Easter (1978) Expansion of the half retinal projection to the tectum in goldfish: An electrophysiological and anatomical study. J. Comp. Neurol. 177:257-278.

Scott, T.M., and G. Lazar (1976) An investigation into the hypothesis of shifting neuronal relationships during development. J. Anat. 121:485496.

Straznicky, C., and J. Hiscock (1984) Post-metamorphic retinal growth in Xenopus. Anat. Embryol. 169:103-109.

Stuermer, C.A.O. (1984) Rules for retinotectal terminal arborizations in the goldfish optic tectum: A whole mount study. J. Comp. Neurol. 229:214232 .

Stuermer, C.A.O., and S.S. Easter, Jr. (1984) Rules of order in the retinotectal fascicles of goldfish. J. Neurosci. 4:1045-1051. 